\title{
Microwave-assisted Extraction of Bioactive Substance from Clinacanthus nutans
}

\author{
Qun YU ${ }^{1, a}$, Wei-wen DUAN ${ }^{2, b}$, Bing LIU ${ }^{1, a}$, Zhen-hua DUAN ${ }^{1,2^{*}, \mathrm{~b}}$ and Fei-fei \\ SHANG ${ }^{2, b}$ \\ ${ }^{1}$ College of Food Science, Hainan University, Haikou \\ ${ }^{2}$ Institue of Food Research, Hezhou University, Hezhou \\ ayuqun930115@163.com, bdzh65@163.com
}

\begin{abstract}
Keywords: Clinacanthus nutans; active substance; microwave-assisted extraction; yield Abstract. Polyphenols, flavonoids, triterpenoid and VitaminC from Clinacanthus nutans were extracted by microwave-assisted extraction (MAE) technology. The optimal extracting conditions were established as distilled water as solvent, solid-liquid ratio 1:45 $(\mathrm{g} / \mathrm{ml})$, irradiation power $160 \mathrm{~W}$, and every extraction cycle of 50s. Results revealed that microwave time exert a significant effect on triterpenoid and VitaminC, whereas irradiation power plays a key role in the extraction of flavonoids. Furthermore, the effect of solid-liquid ratio on polyphenols is obvious. Under these conditions the extraction yield of each component were: polyphenols $8.382 \mathrm{mg} / \mathrm{g}$, flavonoids 24.928 $\mathrm{mg} / \mathrm{g}$, triterpenoid $14.058 \mathrm{mg} / \mathrm{g}$, vitaminC $0.129 \mathrm{mg} / \mathrm{g}$. This study shows that MAE is an efficient technology to extract bioactive substances from leaves and Clinacanthus nutans could potentially be a resource for natural antioxidants.
\end{abstract}

\section{Introduction}

Clinacanthus nutans, a member of Acanthaceae family, commonly called Torsional order flowers or The Green Arrow, is a magnificant herbaceous plant which originates from Malaysia and Java[1]. In the southern provinces of China, it has been cultivated as a medicinal plant. According to the survey, more than 75.33 hectares of Clinacanthus nutans has been planted in Hainan province. Although there are several reports describing the kinds of Clinacanthus nutans, primarily including Clinacanthus nutans tea, Clinacanthus nutans fresh leaves and Clinacanthus nutans powder. Related research of deep processing for Clinacanthus nutans is less. Zhang Weihua extracts total flavonoids from Clinacanthus nutans by ultrasonic-assisted technology[2]. Besides, Liu Xu finds that n-butanol extract of Clinacanthus nutans has inhibitive effect on Heps liver cancer in mice[3]. Clinacanthus nutans also contains some other high value bioactive components, including polyphenols, flavonoids, triterpene and vitamins, and so on. Its extracts are described as presenting anti-aging, antioxidant and immune modulation effects, and these effects are associated with the presence of polyphenols, flavonoids, triterpene and vitamins[4-8]. Microwave-assisted extraction (MAE) is a process that it improves solvent extraction temperature and isolates the required compounds from sample matrix through microwave energy[9]. The application of microwave energy for sample preparation was first applied in the gossypol from cottonseed in 1986. Microwave energy is a non-ionizing radiation, which can penetrate into certain materials and interact with the polar components to generate heat. Heating of microwave energy acts directly on molecules by ionic conduction and rotation of dipoles. In contrast, extracts obtained with the conventional Soxhlet method were very poor in minority bioactive compounds. One of the main advantages of using MAE is the reduction of extraction time, which can mainly be attributed to the difference in the heating performance of microwave and conventional heating. Since then MAE has attracted growing interest, and it is called Green extraction technology because of its high efficiency, low consumption and less pollution[10,11]. Thus, the aims of this study is to optimize the process of extracting the bioactive substances from Clinacanthus nutans by microwave-assisted. Various parameters of MAE were studied including microwave time, irradiation power and solid-liquid ratio. The optimal extracting conditions have been determined to provide a reference for the further development and utilization of Clinacanthus nutans. 


\section{MATERIALS and METHODS}

\section{Materials and Chemicals}

Clinacanthus nutans powder: Wuzhishan Wanjiabao science and technology company limited in Hainan; Gallic acid standard, Rutin standard, Oleanolic acid, Vanillic aldehyde: Yuanye biological science and technology company limited in Shanghai; the Forint phenol standard: Suolaibao science and technology company limited in Beijing; Others' pure is analytical; The water is distilled water.

\section{Instruments preparationMethods}

NJL07-3 experiment for microwave oven: Jiequan microwave equipment company limited in Nanjing; 7200 visible spectrophotometer: Longnike equipment company limited in Shanghai; BS124S electronic scales: Sartorius company; HH-S26S electric-heated thermostatic water bath: Dadi automation instrument company in Jintan; TDZ5-WS pipe rack automatic balance centrifuge: Xiangyi laboratory instrument development company limited in Hunan; SW-CJ-IF single double-sided clean bench: Suzhou purification equipment limited company; BCD-180 refrigerators: Zhujiang refrigerator factory in Guangdong.

\section{Methods}

\section{Determination method of the polyphenols yield}

The method to determine the yield of polyphenols was according to Xu's[12] with some modifications. $20 \mathrm{mg}$ gallic acid was dissolved into a $200 \mathrm{~mL}$ volumetric flask with distilled water to be stock solution. $0.0,0.1,0.2,0.3,0.4$ and $0.5 \mathrm{~mL}$ stock solution were moved to another vitro and diluted with water into $0.5 \mathrm{~mL}$. Add $10 \%$ FC reagent $2.5 \mathrm{~mL}$ and shake completely. After $5 \mathrm{~min} 7.5 \%$ $\mathrm{NaCO}_{3}$ is added in it. Fetch it into Water bath pot for $5 \mathrm{~min}$ under $50 \square$. Keep it in dark place for $1 \mathrm{~h}$ at room temperature. The adsorption of different samples were measured by UV spectrophotometer at $760 \mathrm{~nm}$. Standard curve of polyphenols can be obtained, as follows:

$$
\mathrm{A}=91.406 \mathrm{C}_{1}+0.0159, \mathrm{r}^{2}=0.9958 \text {. }
$$

In accordance with the above standard curve measuring method, $0.5 \mathrm{~mL}$ extracting solution was moved into the colorimetric wareand the absorbance was measured by UV spectrophotometer. The polyphenols concentration was obtained by Eq.1.

Polyphenols yield $(\mathrm{mg} / \mathrm{g})=100 \mathrm{C}_{1} \times \mathrm{V}_{1} / \mathrm{m}\left(\mathrm{C}_{1}\right.$ : the quality concentration of the polyphenols, $\mathrm{V}_{1}$ : the volume of fluid under test, $\mathrm{m}$ : the qualityof Clinacanthus nutans).

\section{Determination method of the flavonoids yield}

The method to determine the yield of flavonoids was according to $\mathrm{Li}$ 's[13] with some modifications. $0.0,0.5,1.0,2.0,3.0,4.0,5.0 \mathrm{~mL}$ Rutin were moved into the volumetric flasks respectively. $0.3 \mathrm{~mL} 5 \%$ sodium nitrite solution was added in it, shaked completely and standed for $6 \mathrm{~min}$. Then add $10 \%$ aluminum nitrate solution $0.3 \mathrm{~mL}$, shake completely and stand for $6 \mathrm{~min} .4 \mathrm{~mL}$ $4 \%$ sodium hydroxide solution was moved in it and diluted with $60 \%$ ethanol into $10 \mathrm{~mL}$. Stand for $12 \mathrm{~min}$. The adsorption of different samples were measured by UV spectrophotometer at $510 \mathrm{~nm}$. Standard curve of flavonoids can be obtained, as follows:

$\mathrm{A}=5.8766 \mathrm{C}_{2}+0.0159, \mathrm{r}^{2}=0.9955$.

In accordance with the above standard curve measuring method, $1 \mathrm{~mL}$ extracting solution was moved into the colorimetric wareand the absorbance was measured by UV spectrophotometer. The flavonoids concentration was obtained by Eq.2.

Flavonoids yield $(\mathrm{mg} / \mathrm{g})=100 \mathrm{C}_{2} \times \mathrm{V}_{2} / \mathrm{m}\left(\mathrm{C}_{2}\right.$ : the quality concentration of the flavonoids, $\mathrm{V}_{2}$ : the volume of fluid under test, $\mathrm{m}$ : the qualityof Clinacanthus nutans).

\section{Determination method of the triterpenoid yield}

The method to determine the yield of triterpenoid was according to Huang's[14] with some modifications. $17 \mathrm{mg}$ Oleanolic acid was moved into volumetric flask accurately. 0.1, 0.2, 0.3, 0.4, $0.5,0.6 \mathrm{~mL}$ standard solution were dissolved into vitros respectively with anhydrous ethanol to $1 \mathrm{~mL} .1 \mathrm{~mL}$ anhydrous ethanol was added into the blank sample. All the vitros were put in a boiling water bath until the solvent volatile completely. $5 \%$ vanillin-ice acetic acid $0.4 \mathrm{~mL}$, perchlorate $1.6 \mathrm{~mL}$ were moved in it respectively and blended quickly. Afterwards $70 \square$ water bath for $15 \mathrm{~min}$, 
cool it to the room temperature with ice water. After $8 \mathrm{~mL}$ ethyl acetate was added, the adsorption of different samples were measured by UV spectrophotometer at $560 \mathrm{~nm}$. Standard curve of triterpenoid can be obtained, as follows:

$\mathrm{A}=42.899 \mathrm{C}_{3}-0.0162, \mathrm{r}^{2}=0.9958$.

In accordance with the above standard curve measuring method, $0.5 \mathrm{~mL}$ extracting solution was moved into the colorimetric wareand the absorbance was measured by UV spectrophotometer. The triterpenoid concentration was obtained by Eq.3.

Triterpenoid yield $(\mathrm{mg} / \mathrm{g})=100 \mathrm{C}_{3} \times \mathrm{V}_{3} / \mathrm{m}\left(\mathrm{C}_{3}\right.$ : the quality concentration of the triterpenoid, $\mathrm{V}_{3}$ : the volume of fluid under test, $\mathrm{m}$ : the qualityof Clinacanthus nutans).

\section{Determination method of the Vitamin $C$ yield}

The method to determine the yield of VitaminC was according to Zhao's[15] with some modifications. $0.2 \mathrm{mg} / \mathrm{mL}$ 2,6-dichloro indophenol solution was stored at $4 \square$. It was calibrated by $0.05 \mathrm{mg} / \mathrm{mL}$ ascorbic acid solution ( it was prepared by $2 \%$ oxalic acid) before each using it. The titer was calculated by Eq.4:

$\mathrm{T}=\mathrm{CV} /\left(\mathrm{V}_{1}-\mathrm{V}_{0}\right)$

$\mathrm{C}$ : concentration of standard ascorbic acid, $\mathrm{V}$ : the volume of standard ascorbic acid solution that have taken, $\mathrm{V}_{0}$ : the volume of 2,6-dichloro indophenol that the blank solution consumed, $\mathrm{V}_{1}$ : the volume of 2,6-dichloro indophenol that the titration consumed.

$10 \mathrm{~mL}$ extracting solution was moved into conical flask and titrated by 2,6-dichloro indophenol. Write down the consumed volume. Vitamin C (mg/100mg) yield was calculated according to Eq.5:

\section{$\mathrm{VC}(\mathrm{mg} / 100 \mathrm{mg})=5\left(\mathrm{~V}_{2}-\mathrm{V}_{0}\right) \mathrm{T} / \mathrm{M}$}

$\mathrm{V}_{0}$ : volume of 2,6-dichloro indophenol that the blank solution consumed, $\mathrm{mL} ; \mathrm{V}_{2}$ : the volume of 2,6-dichloro indophenol that the titration consumed, $\mathrm{mL}$; $\mathrm{T}$ : the titer, $\mathrm{mg} / \mathrm{mL}$; $\mathrm{M}$ : the quality of Clinacanthus nutans,g.

\section{Design of extraction test}

The single factor test: according to the results of preliminary experiments, microwave power( $80 \mathrm{~W}$, $160 \mathrm{~W}, 240 \mathrm{~W}, 320 \mathrm{~W}, 400 \mathrm{~W})$, microwave time(20s, 40s, 60s, 80s, 100s) and solid-liquid ratio(1:20, 1:30, 1:40, 1:50, 1:60) were elected to the factors of the single factor test. Under the condition that other factors are invariable, make a research on every factor's influence on the yield of polyphenols, flavonoids, triterpenoid and VC from Clinacanthus nutans.

Orthogonal test: based on the result of the single factor test, process of microwave-assisted extraction is optimized by the orthogonal experiment. The design of factors and levels is shown in Table1.

Table 1 Factors and their levels in orthogonal array design

\begin{tabular}{cccc}
\hline & \multicolumn{3}{c}{ factor } \\
\cline { 2 - 4 } level & A & B & C \\
& irradiation power(W) & Microwave time(s) & solid-liquid ratio \\
\hline 1 & 120 & 50 & $1: 35$ \\
2 & 160 & 60 & $1: 40$ \\
3 & 200 & 70 & $1: 45$ \\
\hline
\end{tabular}




\section{RESULTS and DISCUSSION}

\section{Results and discussion of the single factor test Effect of irradiation power on yield}

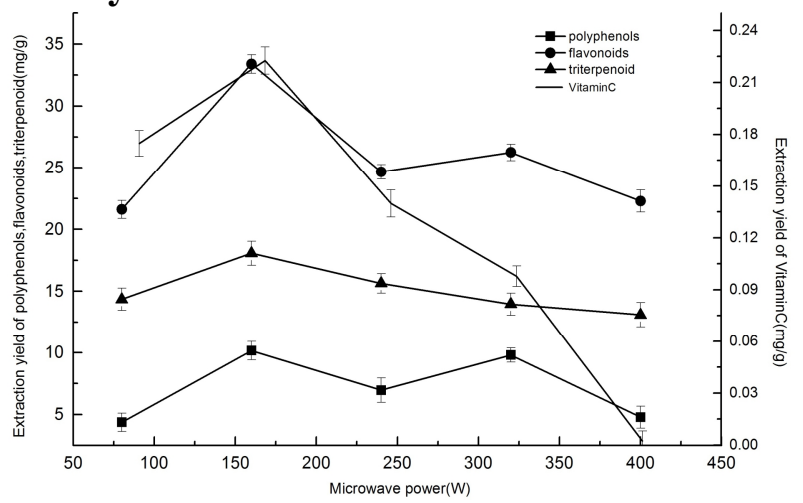

Fig.1 Effect of microwave power on yield

The effect of microwave irradiation power on yields of polyphenols, flavonoids, triterpenoid and VitaminC was evaluated. The rest of the variables were a solid-liquid ratio of $1: 40 \mathrm{~g} / \mathrm{mL}$ and every extraction cycle of $60 \mathrm{~s}$ each. Figure 1 shows that as the power increased, the yields of bioactive ingredients were gradually enhanced. This is perhaps because that microwave power become higher, the material can absorb more microwave energy, which increases damage of the sample cell and is good for leaching the active ingredients[16]. However, when the microwave power was more than $160 \mathrm{~W}$, the yields showed a declining trend. As shown in Figure 1, high microwave irradiation power does not result in high yields of bioactive ingredients. It was speculated that the superfluous energy offered by high irradiation power disturbed the molecular interactions. It leads to partial carbonize of samples as internal overheating and the isomerization or degradation of polyphenols, flavonoids, triterpenoid and VitaminC. Among them, the change trend of VC is the most obvious, and microwave power is the most significant factor for $\mathrm{VC}$; the change trend of triterpenoid is gentle during the process; the yield of polyphenols and flavonoids increases again when microwave power is $320 \mathrm{~W}$, and it is possiblity that the increasing microwave power breaks the cell which is broken incompletely. But they didn't reach the maximum value. Therefore, it was appropriate to select $160 \mathrm{~W}$ as the practical microwave irradiation power.

\section{Effect of microwave time on yield}

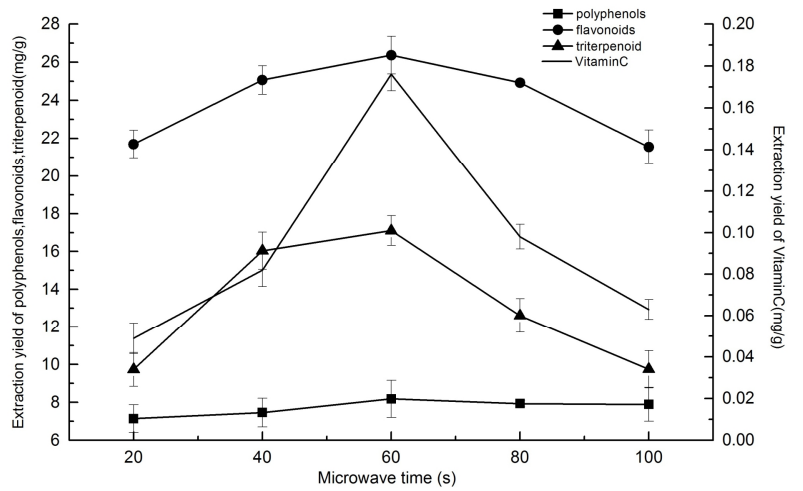

Fig.2 Effect of microwave treatment time on yield

Microwave irradiation is able to generate sufficient energy in a short time. Thus, microwave irradiation time should be controlled properly. The rest of the variables were a solid-liquid ratio of 1:40 $\mathrm{g} / \mathrm{mL}$ and microwave irradiation power of $160 \mathrm{~W}$. The yields of bioactive substances after various extractions are shown in Figure 2. It was observed that 60s of irradiation time can increase the yields and prolonged irradiation led to a reduction in yields. The highest yield was obtained after $160 \mathrm{~W}$ for 60 s's extraction. Because the longer time will increase that microwave energy of the moisture from the substrate accumulates. It's more obvious to destruct the cell wall. So that the yield of the four active substances increases[17]. Time played an important role on the yields. When 
microwave irradiation time increases from 60 to 100s, the yields of four target analytes decrease dramatically. Different bioactive substance present different trend. This phenomenon is relevant with their molecular structure. The nature of the material is decided by the structure of the material. Long time of microwave radiation damages the structure of molecules, decreases the yield, which is bad for the extraction of active substances. Thus, 60s was deemed as the optimal microwave irradiation time.

\section{Effect of solid-liquid ratio on yield}

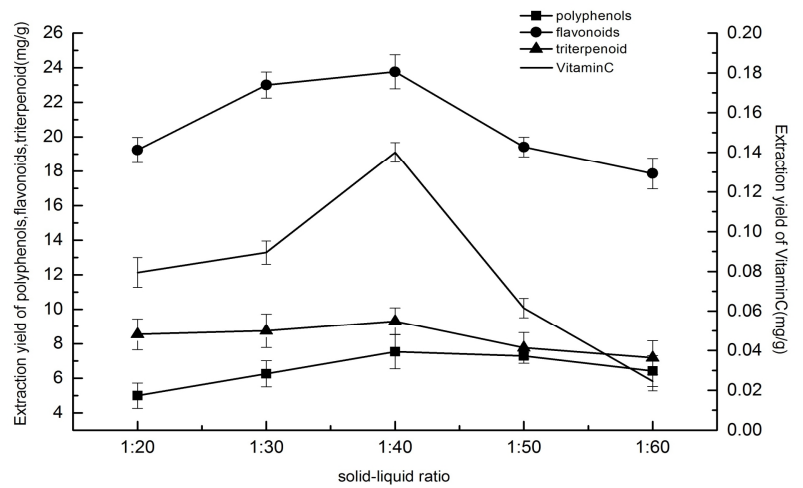

Fig.3 Effect of solid-liquid ratio on yield

Solid-liquid ratio is an important factor in separation technique. To avoid inadequate extraction, the effect of solid-liquid ratio on the yields of polyphenols, flavonoids, triterpenoid and VitaminC were studied with different solid-liquid ratios (1:20, 1:30, 1:40, 1:50, 1:60 g/mL) under a microwave irradiation power of $160 \mathrm{~W}$ and an extraction time of $60 \mathrm{~s}$. In Figure 3, the yields of bioactive substances increase dramatically with the increasing of solid-liquid ratios from 1:20 to 1:40 g/mL; the yields is the highest when solid-liquid ratio is $1: 40 \mathrm{~g} / \mathrm{mL}$; while solid-liquid ratios are higher than $1: 40 \mathrm{~g} / \mathrm{mL}$, high solid-liquid ratios bring a decrease of their yields. Suitable solid-liquid ratio can make Clinacanthus nutans dissolve completely and avoid excessive solvent dispersing microwave energy. Among them, triterpenoid and polyphenols change gently during this process; the yield of $\mathrm{VC}$ and flavonoids decreases obviously after 1:40. Thus, taking the consumption of solvent into account, the solid-liquid ratio in present test was identified as 1:40 g/mL.

\section{Results and discussion of orthogonal test}

Orthogonal experimental design was employed to optimize the MAE process of polyphenols, flavonoids, triterpenoid and VitaminC, and results are shown in Table 2. It shows that solid-liquid ratio is the most significant factor while extraction time is the insignificant for the polyphenols yield, in an order of $\mathrm{C}>\mathrm{A}>\mathrm{B}$, and the optimal level is $\mathrm{A}_{3} \mathrm{~B}_{3} \mathrm{C}_{3}$; microwave irradiation power is the most significant factor while solid-liquid ratio is the insignificant for the flavonoids yield, in an order of $\mathrm{A}>\mathrm{B}>\mathrm{C}$, and the optimal level is $\mathrm{A}_{2} \mathrm{~B}_{3} \mathrm{C}_{2}$; extraction time is the most significant factor while microwave irradiation power is the insignificant for the triterpenoid yield, in an order $\mathrm{B}>\mathrm{C}>\mathrm{A}$, and the optimal level is $\mathrm{A}_{2} \mathrm{~B}_{1} \mathrm{C}_{3}$; extraction time is the most significant factor while solid-liquid ratio is the insignificant for the VitaminC yield, in an order of $\mathrm{B}>\mathrm{A}>\mathrm{C}$, and the optimal level is $\mathrm{A}_{2} \mathrm{~B}_{1} \mathrm{C}_{3}$. Considering that microwave power is the most significant influence on flavonoids, so the best microwave power $160 \mathrm{~W}$ of flavonoids is elected as the optimal microwave power; microwave time is the most significant influence on triterpenoid and VitaminC, so the best microwave time 50s of triterpenoid and VitaminC is elected as the optimal microwave time; solid-liquid ratio is the most significant influence on polyphenols, so the best solid-liquid ratio 1:45 $\mathrm{mg} / \mathrm{mL}$ of polyphenols is elected as the optimal solid-liquid ratio. According to this experimental design, the optimum conditions for MAE of polyphenols, flavonoids, triterpenoid and VitaminC from Clinacanthus nutans are that microwave irradiation power of $160 \mathrm{~W}$, microwave time of 50s and solid-liquid ratio of 1:45 $\mathrm{g} / \mathrm{mL}$.

Confirmation experiments were carried out at these best conditions, and the yields of polyphenols, flavonoids, triterpenoid and VitaminC were $8.382 \mathrm{mg} / \mathrm{g}, 24.928 \mathrm{mg} / \mathrm{g}, 14.058 \mathrm{mg} / \mathrm{g}$ and $0.129 \mathrm{mg} / \mathrm{g}$, which were in good agreement with the predicted. 


\begin{tabular}{|c|c|c|c|c|c|c|c|}
\hline No. & A & B & $\mathrm{C}$ & $\begin{array}{l}\text { Polyphenols } \\
\text { (mg/g) }\end{array}$ & $\begin{array}{l}\text { flavonoids } \\
\text { (mg/g) }\end{array}$ & $\begin{array}{l}\text { triterpenoid } \\
\quad(\mathrm{mg} / \mathrm{g})\end{array}$ & $\begin{array}{l}\text { VitaminC } \\
(\mathrm{mg} / \mathrm{g})\end{array}$ \\
\hline 1 & 1 & 1 & 1 & 6.768 & 23.408 & 11.560 & 0.057 \\
\hline 2 & 1 & 2 & 2 & 7.317 & 21.813 & 11.455 & 0.054 \\
\hline 3 & 1 & 3 & 3 & 8.116 & 22.189 & 10.970 & 0.045 \\
\hline 4 & 2 & 1 & 2 & 7.430 & 24.088 & 11.822 & 0.094 \\
\hline 5 & 2 & 2 & 3 & 7.973 & 24.573 & 9.669 & 0.076 \\
\hline 6 & 2 & 3 & 1 & 6.824 & 25.343 & 12.642 & 0.067 \\
\hline 7 & 3 & 1 & 3 & 8.150 & 24.099 & 13.952 & 0.132 \\
\hline 8 & 3 & 2 & 1 & 6.875 & 21.352 & 10.068 & 0.049 \\
\hline 9 & 3 & 3 & 2 & 7.414 & 24.999 & 9.517 & 0.039 \\
\hline \multirow{4}{*}{$\begin{array}{l}\text { polyphenols } \\
\text { (mg/g) }\end{array}$} & 7.400 & 7.449 & 6.822 & \multirow{2}{*}{\multicolumn{2}{|c|}{ order }} & \multirow{2}{*}{\multicolumn{2}{|c|}{ the optimal level }} \\
\hline & 7.409 & 7.388 & 7.387 & & & & \\
\hline & 7.480 & 7.451 & 8.080 & \multirow{2}{*}{\multicolumn{2}{|c|}{$\mathrm{C}>\mathrm{A}>\mathrm{B}$}} & \multicolumn{2}{|c|}{$\mathrm{A}_{3} \mathrm{~B}_{3} \mathrm{C}_{3}$} \\
\hline & 0.080 & 0.063 & 1.258 & & & & \\
\hline \multirow{5}{*}{$\begin{array}{l}\text { flavonoids } \\
\text { (mg/g) }\end{array}$} & 22.470 & 23.865 & 23.368 & \multirow{2}{*}{\multicolumn{2}{|c|}{ order }} & \multirow{2}{*}{\multicolumn{2}{|c|}{ the optimal level }} \\
\hline & 24.668 & 22.579 & 23.633 & & & & \\
\hline & 23.483 & 24.177 & 23.620 & \multicolumn{2}{|c|}{$\mathrm{A}>\mathrm{B}>\mathrm{C}$} & \multicolumn{2}{|c|}{$\mathrm{A}_{2} \mathrm{~B}_{3} \mathrm{C}_{2}$} \\
\hline & 2.198 & 1.598 & 0.265 & & & & \\
\hline & 11.328 & 12.445 & 11.423 & \multirow{2}{*}{\multicolumn{2}{|c|}{ order }} & \multirow{2}{*}{\multicolumn{2}{|c|}{ the optimal level }} \\
\hline \multirow{3}{*}{$\begin{array}{l}\text { triterpenoid } \\
\text { (mg/g) }\end{array}$} & 11.378 & 10.397 & 10.931 & & & & \\
\hline & 11.179 & 11.043 & 11.530 & \multirow{2}{*}{\multicolumn{2}{|c|}{$\mathrm{B}>\mathrm{C}>\mathrm{A}$}} & \multicolumn{2}{|c|}{$\mathrm{A}_{2} \mathrm{~B}_{1} \mathrm{C}_{3}$} \\
\hline & 0.199 & 2.048 & 0.599 & & & \multirow{3}{*}{\multicolumn{2}{|c|}{ the optimal level }} \\
\hline \multirow{4}{*}{$\begin{array}{l}\text { VitaminC } \\
\text { (mg/g) }\end{array}$} & 0.052 & 0.094 & 0.058 & \multirow{2}{*}{\multicolumn{2}{|c|}{ order }} & & \\
\hline & 0.079 & 0.060 & 0.062 & & & & \\
\hline & 0.073 & 0.050 & 0.084 & \multirow{2}{*}{\multicolumn{2}{|c|}{$\mathrm{B}>\mathrm{A}>\mathrm{C}$}} & \multirow{2}{*}{\multicolumn{2}{|c|}{$\mathrm{A}_{2} \mathrm{~B}_{1} \mathrm{C}_{3}$}} \\
\hline & 0.027 & 0.044 & 0.026 & & & & \\
\hline
\end{tabular}

Table 2 Results of orthogonal test

\section{CONCLUSION}

This study focused on the optimization of MAE extraction process for bioactive substances (polyphenols, flavonoids, triterpenoid, VitaminC) from Clinacanthus nutans. The maximum extraction yields were obtained for $160 \mathrm{~W}$ as irradiation power for 50s as processing time, higher for that obtained with a conventional method. Analyse the result of single factor test by Origin9.0. The study shows that: order of the polyphenols yield is solid-liquid ratio>microwave irradiation power $>$ microwave time; order of the flavonoids yield is microwave irradiation power $>$ microwave time>solid-liquid ratio; order of the triterpenoid yield is microwave time>solid-liquid ratio >microwave irradiation power; order of the $\mathrm{VC}$ yield is microwave time $>$ microwave irradiation power> solid- liquid ratio.

According to the above experiments, the optimum MAE conditions were determined to be: microwave irradiation time of 50s, microwave irradiation power of $160 \mathrm{~W}$ and solid-liquid ratio of 1:45 $\mathrm{g} / \mathrm{mL}$. It's desirable to extract the active substances from Clinacanthus nutans under the conditions. Further investigation on the antioxidant and antimicrobial activity of the recovered 
phytocompounds obtained by microwave pre-treatment is essential to determine the bioactive activity of the extracts.

\section{References}

[1] Lin JT, Li HM, Yu JG. CHM, 1983, 14(8):337.(In Chinese)

[2] Yi B, Xu WT, Deng D, et al. CJETMF, 2014,20(19):38-41.(In Chinese)

[3] Liu X, GuoW J, HuangD M, et al. Journal of Jiangsu University (Medicine Edition), 2014,24(3): 211-215.(In Chinese)

[4] Yi B, Xu WT, Deng D, et al. Pharm J Chin PLA, 2012,28(5):396.(In Chinese)

[5] $\mathrm{Yu} \mathrm{Q}$, Duan $\mathrm{ZH}$, Duan WW, et al. Analysis and evaluation of nutrition composition of Clinacanthus nutans [A].Xie Liquan. Proceedings of the 2nd technical congress on resources, environment and engineering (CREE 2015)[C]. London: CRC Press.

[6] Duan ZH, Sun XL, Wang JL. Food Science,2009,30(16):149-152.(In Chinese)

[7] $\mathrm{Xu}$ SF. Studies on chemical components and the immunoregulatory activity from WingedCassoa. Taiwan: Kaohsiung Medical University, Phd. 2012.(In Chinese)

[8] Dampawan P, Huntrakul C, Reutrakul V, et al. Constituents of Clinacanthus nutans and the crystal structure of LUP-20(29)-ene-3-one. J Sci Soc Thai, 1977,3:14.

[9] Yao JH, Du Y, Xiao L. Journal of Biology, 2007, 24(6):61-63.(In Chinese)

[10] Guo JQ. Tianjin Pharmacy, 2010,22(4):63-65. (In Chinese)

[11] Liu F, Huang KR, Li YC. Chinese Agricultural Science Bulletin, 2012,28(3):290-294.(In Chinese)

[12] Xu HY, Sun XD, Zhang PJ, et al. Food Research and Development, 2009,30(3):126-128.(In Chinese)

[13] Li PJ, Liu XG, Long HR, et al. Food Science and Technology, 2011,36(01):167-171. (In Chinese)

[16] Li XX, Zhang JH, Guan HL, et al. Food Research and Development, 2013,34(19):39-41. (In Chinese)

[14] Huang SQ, Yao SJ, Liu CL, et al. Modern Food Science and Technology, 2011,27(8):10151019.(In Chinese)

[15] Zhao XM, Jiang Y, Wu YP. Food Science, 2006,27(3):197-199. (In Chinese)

[17] Huang XR, Li CZ, Chen YH, et al. Nat Prod Res Dev, 2013,25:395-397,394.(In Chinese) 